\title{
Manganese oxides/LaMnO 3 perovskite materials and their application in the oxygen reduction reaction
}

\author{
J.X. Flores-Lasluisa a , F. Huerta ${ }^{\text {b}}$, D. Cazorla-Amorós ${ }^{c}$, E. Morallón ${ }^{\text {a, ** }}$ \\ ${ }^{a}$ Dept. Química Física e Instituto Universitario de Materiales, Universidad de Alicante, Ap. 99, E-03080, Alicante, Spain \\ ${ }^{\mathrm{b}}$ Dept. Ingenieria Textil y Papelera, Universitat Politecnica de Valencia, Plaza Ferrandiz y Carbonell, 1. E-03801, Alcoy, Spain \\ ${ }^{\mathrm{c}}$ Dept. Química Inorgánica e Instituto Universitario de Materiales, Universidad de Alicante, Ap. 99, E-03080, Alicante, Spain
}

\section{A R T I C L E I N F O}

\section{Article history:}

Received 29 September 2021

Received in revised form

8 February 2022

Accepted 9 February 2022

Available online 11 February 2022

\section{Keywords:}

Oxygen reduction reaction

$\mathrm{LaMnO}_{3}$ perovskite

Manganese oxygen

Carbon black

Synergistic effect

\begin{abstract}
A B S T R A C T
Manganese-based materials can catalyze the oxygen reduction reaction (ORR), although their activity is known to depend on the crystalline phases and on the concentration of surface-active species. In the present study, we have optimized these two parameters to obtain improved catalysts for ORR. A sol-gel method was used to synthesize $\mathrm{LaMnO}_{3}$-manganese oxides composites with different lanthanum-tomanganese atomic ratios. The synthesized materials, which can be described as $\mathrm{La}_{1-\mathrm{x}} \mathrm{MnO}_{\mathrm{z}}$, were tested under ORR conditions and characterized by several physicochemical techniques such as SEM, XPS, EDX or XRD. It was found that the concentration of lanthanum governs the formation of different crystal phases and determines the crystallite size. Besides, high values of $x$ tend to increase the surface concentration of manganese and therefore to produce more active sites for ORR. Among the materials analysed, $\mathrm{La}_{0.6} \mathrm{MnO}_{z}$ mixed with carbon black (Vulcan) showed the best electrocatalytic performance. The high tolerance to methanol makes this electrocatalyst a promising alternative to substitute Pt-based materials in alkaline electrolytes.
\end{abstract}

๑) 2022 Published by Elsevier Ltd.

\section{Introduction}

The oxygen reduction reaction (ORR) plays an important role in the development of energy conversion devices such as fuel cells and metal-air batteries [1,2]. Since this reaction exhibits slow kinetics, a suitable catalyst is often required to carry it out $[3,4]$. At present, the most used materials are those based on platinum, which show excellent catalytic performance but are scarce and expensive [5-7]. Usually, two main strategies have been followed to reduce the usage of platinum and to increase the catalytic performance for ORR: i) synthesis of nanostructured catalysts with high active surface area [5] and ii) synthesis of Pt-based alloys containing transition [6] or other precious metals [7], which can improve the overall catalytic performance. In this context, the development of new catalysts based on more abundant elements is essential. Transition metals can adopt various oxidation states, which makes them ideal for electrocatalytic applications [8,9]. In fact, several studies have been devoted to the development of metal oxide catalysts based on cobalt, manganese, iron or copper [10-13].

\footnotetext{
* Corresponding author.

E-mail address: morallon@ua.es (E. Morallón).
}

In particular, manganese containing oxides have attracted considerable attention due to their high stability, diverse oxidation states and good performance for ORR [14]. Both crystal structure and morphology have been reported to influence their catalytic performance. For example, $\mathrm{MnO}_{2}$ can be synthesized with different structures, namely $\alpha-\mathrm{MnO}_{2}$ and $\beta-\mathrm{MnO}_{2}$, but it seems that $\alpha-\mathrm{MnO}_{2}$ shows higher surface area and activity towards ORR [11]. The capability of $\mathrm{Mn}_{2} \mathrm{O}_{3}$-based compounds to catalyze the 4-electron pathway of the ORR mechanism was also reported $[17,18]$ and some researchers considered $\mathrm{Mn}_{3} \mathrm{O}_{4}$ as an interesting material for this reaction because of the mixed-valence of $\mathrm{Mn}$. However, due to its intrinsic low conductivity, $\mathrm{Mn}_{3} \mathrm{O}_{4}$ has been combined with conductive components, such as doped carbons, to improve catalytic activity $[15,16]$. Apart from conducting substrates, manganese oxides can be combined with other transition metals to tune their electrocatalytic properties. The presence of two redox couples usually increases the electrical conductivity and, in addition, the synergistic effect that sometimes appears between the two cations can enhance the overall activity of the materials [19-23]. Particularly, the combination of manganese and cobalt to form cubic spinel oxides showed excellent performance towards ORR [19,20] because more active sites are available in this crystal structure. 
Manganese oxides based on the perovskite structure $\mathrm{AMnO}_{3}$, where A is a rare-earth metal, also show high ORR activity [24]. Among different A-cations, lanthanum provides the highest catalytic activity, which in part is ascribed to the larger electrical conductivity of this material [25]. In addition, the higher size of $\mathrm{La}^{3+}$ produces more symmetrical structures, thus reducing both distortion and rotation of the $\mathrm{BO}_{6}$ octahedron $[26,27]$. Previous studies [28-30] reported that $\mathrm{LaMnO}_{3}$ perovskite shows the best performance towards ORR because most $\mathrm{Mn}$ atoms, which actively participate in the reaction mechanism, show one electron in their $e_{g}$ orbitals. This brings moderate interaction between $\mathrm{B}$ sites and oxygen species [31]. To increase the activity of $\mathrm{LaMnO}_{3}$, partial substitution of manganese with cobalt has been suggested. The positive effect was ascribed to the synergy between both cations and to the presence of oxygen vacancies. Another strategy to increase the electrocatalytic performance of lanthanum-based perovskites in ORR is to substitute partially La with $\mathrm{Sr}$ or Y. The presence of oxygen vacancies seems to improve both the oxygen adsorption/desorption capability and the electrical conductivity [32]. In addition, the partial substitution promotes $\mathrm{Mn}^{4+}$ redox state, which shows higher oxidation ability and enhances the covalency of the $\mathrm{Mn}-\mathrm{O}$ bond, thus favouring the electron transfer [33]. The surface concentration of $\mathrm{Mn}^{4+}$ can be modulated after synthesis [34] or previously, by slightly adjusting the La:Mn ratio [35]. In both cases an enhancement of the electrochemical response was observed.

Due to low surface area and electrical conductivity, which hinder the electron transfer and decrease the number of active sites, manganese oxide-based materials usually show limitations in electrocatalytic reactions $[17,36]$. To overcome these disadvantages, two different approaches have been followed: synthesis of nanoscale catalysts or a combination with highly conducting compounds, such as carbon materials [20,37,38]. Several authors reported a synergistic effect between metal oxides and carbon materials that enhances ORR activity [39-41]. Apart from providing electrical conductivity, the carbon component can act as a cocatalyst $[38,42]$ and also favours the regeneration of catalytic Mn sites [41].

In the present study, we develop Mn-based materials by tailoring the crystal phases and the surface concentration of active manganese. $\mathrm{LaMnO}_{3} / \mathrm{Mn}_{\mathrm{a}} \mathrm{O}_{\mathrm{b}}\left(\mathrm{La}_{1-\mathrm{x}} \mathrm{MnO}_{\mathrm{z}}\right.$ where $x$ is in the range from 0 to 0.5 ) composites are mixed with Vulcan XC-72R carbon black to study the ORR. The synthesized materials are characterized by different physicochemical and electrochemical techniques and the electrocatalytic activity of the composites is analysed.

\section{Experimental}

\subsection{Materials and reagents}

The reagents employed for the synthesis of perovskite oxides were lanthanum (III) nitrate hexahydrate $\left(\mathrm{La}\left(\mathrm{NO}_{3}\right)_{3} \square 6 \mathrm{H}_{2} \mathrm{O}\right)$ (Sigma-Aldrich, 99.99\%), manganese (II) nitrate hydrate $\left(\mathrm{Mn}\left(\mathrm{NO}_{3}\right)_{2} \square \mathrm{xH}_{2} \mathrm{O}\right.$ ) (Alfa Aesar, 99.98\%), citric acid (Sigma-Aldrich 99\%), ethylenediaminetetraacetic acid (EDTA) (Sigma-Aldrich, ACS reagent) and ammonia $\left(\mathrm{NH}_{3}\right)$ (VWR Chemicals, analytic reagent).

Besides, commercial Vulcan XC-72R carbon black (Vulcan) (Cabot Corporation), potassium hydroxide (KOH) (VWR Chemicals), isopropanol $99.5 \%$ (Acros. Organics), Nafion ${ }^{\circledR} 5 \% \mathrm{w} / \mathrm{w}$ water and 1 propanol (Alfa Aesar) and $20 \% \mathrm{wt} \mathrm{Pt} / \mathrm{C}$ (Sigma-Aldrich) were also used. The solutions were prepared using ultrapure water (18 M $\Omega$ / $\mathrm{cm}$ from an Elga Labwater Purelab system) and the gases, $\mathrm{N}_{2}$ (99.999\%), $\mathrm{O}_{2}$ (99.995\%) and $\mathrm{H}_{2}(99.999 \%)$ were provided by Air Liquide.

\subsection{Synthesis of composites}

The synthesis of $\mathrm{LaMnO}_{3} / \mathrm{Mn}_{\mathrm{a}} \mathrm{O}_{\mathrm{b}}$ was performed by a sol-gel method similar to that described in the literature [43]. The La:Mn atomic ratio was modified according to the expression $\mathrm{La}_{1-\mathrm{x}} \mathrm{MnO}_{\mathrm{z}}$ $(\mathrm{x}=0,0.1,0.3,0.4$, and 0.5$) . \mathrm{Mn}_{\mathrm{a}} \mathrm{O}_{\mathrm{b}}$ oxide materials were synthesized under the same protocol, but without lanthanum precursors. The calcination temperature was $700{ }^{\circ} \mathrm{C}$ for $\mathrm{Mn}_{2} \mathrm{O}_{3}$ and $1000^{\circ} \mathrm{C}$ for $\mathrm{Mn}_{3} \mathrm{O}_{4}$.

The $\mathrm{La}_{1-\mathrm{x}} \mathrm{MnO}_{\mathrm{z}} /$ Vulcan and $\mathrm{Mn}_{\mathrm{a}} \mathrm{O}_{\mathrm{b}} /$ Vulcan materials were prepared by physically mixing both solids, at 1:1 wt ratio, in an agate mortar until a homogenous material was obtained.

\subsection{Physicochemical characterization techniques}

The morphologies of samples were analysed by scanning electron microscopy (SEM, Hitachi S-3000 N, Chiyoda, Japan). The bulk composition of the metal oxides was studied by energy-dispersive $\mathrm{X}$-ray spectroscopy (EDX) with an X-ray detector device attached to the SEM.

The crystallographic parameters of the metal oxide materials were characterized by X-ray diffraction (XRD) employing $\mathrm{Cu} \mathrm{K} \alpha$ radiation source at a step of $0.05^{\circ}$ in the $2 \theta$ range from $10^{\circ}$ to $80^{\circ}$ using a Bruker D8 Advance diffractometer (Billerica, USA) with Goebel (non-planar samples) with an X-ray generator KRISTALLOFLEX K 760-80F (power: $3000 \mathrm{~W}$, voltage: 20-60 KV and current:5-80 mA). To estimate the crystallite size, the Scherrer equation was applied [44]:

$$
\mathrm{D}_{\mathrm{c}}=\frac{k \lambda}{\beta \cos (\theta)}
$$

where $D_{c}$ is the crystallite size (nm); $k$ is the constant related to the grain shape whose value is $0.89 ; \lambda$ is the wavelength of the radiation source used whose value is $0.15406 \mathrm{~nm} ; \beta$ corresponds to the full width at half maximum (FWHM) (radians), and $\theta$ is the Bragg angle. Crystalline quartz was employed to correct the instrumental broadening factor from the measured FWHM value. To calculate the corrected FWHM value, the following equation was used [44]:

$\beta_{\text {real }}^{2}=\beta_{\text {obs }}^{2}-\beta_{\text {inst }}^{2}$

where $\beta_{\text {real }}$ is a value obtained from the crystal, $\beta_{\text {obs }}$ is the measured value, and $\beta_{\text {inst }}$ is the value associated with the instrument obtained from the quartz pattern.

The concentration of the different crystal phases present in the composites was obtained by using the Rietveld refinement function of the Highscore Plus software.

The surface composition of the metal oxides materials was characterized by X-ray photoelectron spectroscopy (XPS) in a VGMicrotech Multilab 3000 equipment (Thermo-Scientific, Waltham, MA, USA), equipped with an $\mathrm{Al} \mathrm{K} \alpha$ radiation source $(1253.6 \mathrm{eV})$. To deconvolute the XPS data, the XPSPEAK41 software was used adjusting the experimental curves with a combination of Lorentz-Gaussian functions and a Shirley line was used as the background.

\subsection{Electrochemical characterization}

The electrochemical properties of $\mathrm{La}_{1-\mathrm{x}} \mathrm{MnO}_{\mathrm{z}} / \mathrm{Vulcan}$ materials were characterized using an ink prepared by sonicating a suspension of $1 \mathrm{mg}$ of material and $1 \mathrm{~mL}$ of a solution ( $20 \mathrm{vol} \%$ isopropanol, 80 vol\% water and 0.02 vol\% Nafion $\left.{ }^{\circledR}\right)$.

Electrochemical measurements were done at $25{ }^{\circ} \mathrm{C}$ in a threeelectrode cell in 0.1 M KOH medium using an Autolab PGSTAT302 
(Metrohm, Netherlands) potentiostat. A rotating ring-disk electrode (RRDE) from Pine Research Instruments (USA), equipped with a glassy carbon (GC) disk (5.61 $\mathrm{mm}$ in diameter) and a Pt ring was used as the working electrode. A graphite rod was used as the counter electrode and a reversible hydrogen electrode (RHE) immersed in the working electrolyte as the reference electrode.

The cyclic voltammetry technique was employed to characterize the samples in an alkaline medium. $120 \mu \mathrm{L}$ of the above suspension was deposited on the glassy carbon disk electrode and a uniform catalyst layer of $480 \mu \mathrm{g} / \mathrm{cm}^{2}$ active material was obtained. The ORR was studied by linear sweep voltammetry (LSV) experiments at $5 \mathrm{mV} / \mathrm{s}$ from 1 to $0 \mathrm{~V}$ (vs RHE) in $0.1 \mathrm{M} \mathrm{KOH}$ medium at $1600 \mathrm{rpm}$. The Pt ring electrode potential was maintained at $1.5 \mathrm{~V}$ during all the measurements. The electron transfer number, $n_{e^{-}}$, was calculated from the hydrogen peroxide oxidation at the Pt ring electrode, according to the following equation [32]:

$\mathrm{HO}_{2}^{-}[\%]=200 \times \frac{\mathrm{I}_{\text {ring }} / \mathrm{N}}{\mathrm{I}_{\text {disk }}+\mathrm{I}_{\text {ring }} / \mathrm{N}}$

$\mathrm{n}_{\mathrm{e}^{-}}=\frac{4 \mathrm{I}_{\text {disk }}}{\mathrm{I}_{\text {disk }}+\mathrm{I}_{\text {ring }} / \mathrm{N}}$

where $I_{\text {disk }}$ and $I_{\text {ring }}$ are the currents measured at disk and ring electrodes, respectively, and $\mathrm{N}$ is the current collection efficiency of the ring, which in this case is 0.37 .

A commercial Pt (20 wt\%) on graphitized carbon (SigmaAldrich) was used as reference electrocatalyst in LSV (Pt/C).

\section{Results and discussion}

\subsection{Surface morphology and structure characterization}

It is known that both surface morphology and crystal structure of active materials have an important impact on electrochemical reactions. Usually, porous structures are preferred because the amount of available active sites increases and the diffusion of reactants and the release of products are facilitated, resulting in a better electrocatalytic performance. The surface morphology of $\mathrm{La}_{1}$ ${ }_{x} \mathrm{MnO}_{z}$ composites and $\mathrm{Mn}_{\mathrm{a}} \mathrm{O}_{\mathrm{b}}$ oxides was characterized by SEM microscopy (Fig. S1). These materials display similar morphology, which consists on agglomerated particles of around $200 \mathrm{~nm}$ showing an irregular shape and providing low porosity development. Usually, increasing the calcination temperature during the synthesis results in higher particle size and lower surface area [45]. This effect is observed for $\mathrm{Mn}_{3} \mathrm{O}_{4}$, which shows large particles of around $800 \mathrm{~nm}$ that might affect its electrocatalytic performance towards ORR.

As shown in previous studies for perovskite-based materials [21,22], more symmetrical crystal structures reduce the distortion and rotation of the $\mathrm{BO}_{6}$ octahedron and facilitate the interaction between reactants and $\mathrm{B}$ site cations. A detailed characterization of the crystal structure of materials can be provided by XRD analysis. XRD patterns obtained from $\mathrm{La}_{1-\mathrm{x}} \mathrm{MnO}_{\mathrm{z}}$ composites and $\mathrm{Mn}_{\mathrm{a}} \mathrm{O}_{\mathrm{b}}$ oxides are presented in Fig. 1, where some differences can be observed. $\mathrm{LaMnO}_{z}$ shows a diffractogram characteristic of pure $\mathrm{LaMnO}_{3}$ that can be indexed to a cubic perovskite phase and belongs to the Pm-3m space group ( $\mathrm{LaMnO}_{3}$, PDF code: 96-154-2146). The crystal structure changes to rhombohedral in the case of $\mathrm{La}_{0.9} \mathrm{MnO}_{\mathrm{z}}$ and $\mathrm{La}_{0.7} \mathrm{MnO}_{\mathrm{z}}$ samples, and it belongs to the space group R-3c ( $\mathrm{LaMnO}_{3}$, PDF code: 96-152-1792). This change is perceived as a double peak at $2 \theta$ around $32^{\circ}$ (see Fig. $1 \mathrm{~b}$ ) but the cubic perovskite phase of $\mathrm{LaMnO}_{3}$ appears again for $\mathrm{La}_{0.6} \mathrm{MnO}_{z}$ and $\mathrm{La}_{0.5} \mathrm{MnO}_{\mathrm{z}}$ samples. From these results it can be deduced that La:Mn ratio plays an important role in the formation of different crystal structures and that the rhombohedral structure is present only for compounds with $0.1 \leq x \leq 0.3$. $\mathrm{LaMnO}_{\mathrm{z}}$ is the only sample exhibiting a pure perovskite structure. The $\mathrm{Mn}_{3} \mathrm{O}_{4}$ oxide is indexed to a tetragonal phase and belongs to the $14_{1} /$ amd space group $\left(\mathrm{Mn}_{3} \mathrm{O}_{4}\right.$, PDF code: 96-101-1263), whereas $\mathrm{Mn}_{2} \mathrm{O}_{3}$ is indexed to a cubic phase and belongs to the Ia- 3 space group $\left(\mathrm{Mn}_{2} \mathrm{O}_{3}\right.$, PDF code: 96-810-3498).

In summary, the main crystalline phases observed for $\mathrm{La}_{1-\mathrm{x}} \mathrm{MnO}_{\mathrm{z}}$ materials are $\mathrm{LaMnO}_{3}, \mathrm{Mn}_{3} \mathrm{O}_{4}$ and $\mathrm{Mn}_{2} \mathrm{O}_{3}$, the former predominating for all compounds in either cubic or rhombohedral pattern. Manganese oxides develop when La:Mn ratio is not equimolar, and, accordingly, the concentration of perovskite form decreases. These effects can be observed in Table 1, with data calculated from Rietveld refinement (Fig. S2 shows the diffraction pattern lines used for the refinement of the $\mathrm{La}_{0.5} \mathrm{MnO}_{z}$ sample).

$\mathrm{Mn}_{3} \mathrm{O}_{4}$ is the first oxide formed in the range $0.1 \leq x \leq 0.5$, whereas $\mathrm{Mn}_{2} \mathrm{O}_{3}$ forms at $x \geq 0.4$, when the cubic structure is restored. These two manganese oxide phases were reported to exhibit good electrocatalytic response towards ORR [14,17]. Since the size of nanoparticles plays an important role in the
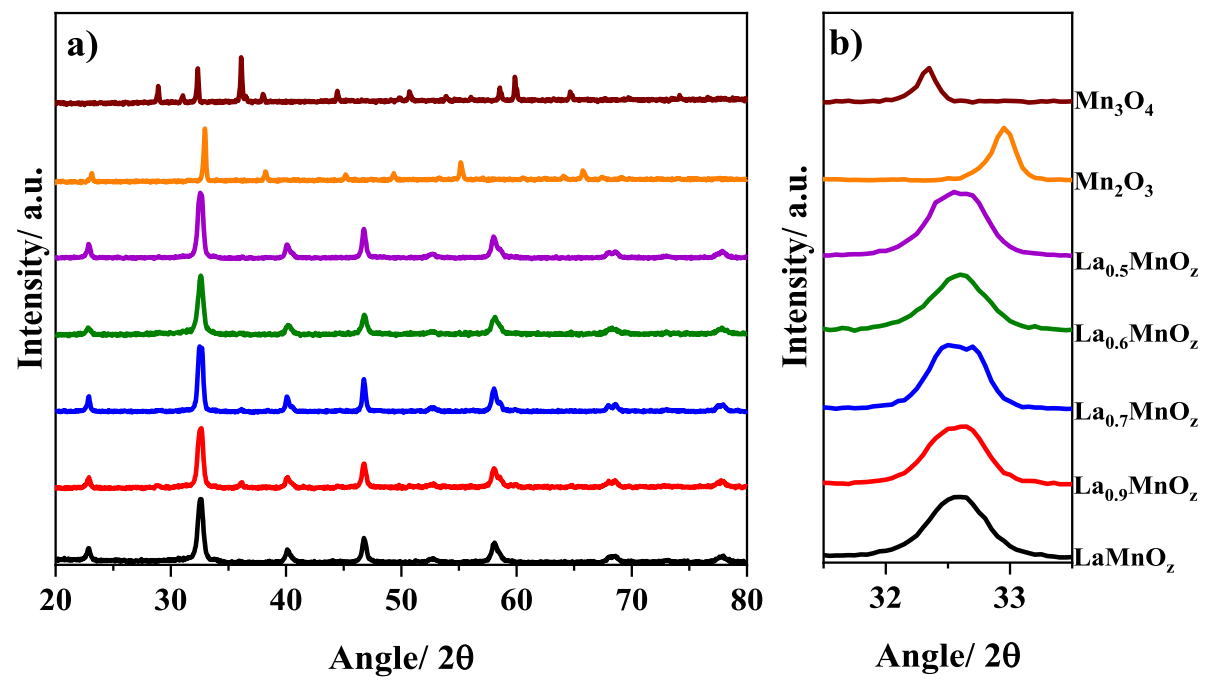

Fig. 1. X-ray diffraction patterns for a set of $\mathrm{La}_{1-\mathrm{x}} \mathrm{MnO}_{z}$ composites and $\mathrm{Mn}_{\mathrm{a}} \mathrm{O}_{\mathrm{b}}$ oxides. 
Table 1

Crystal phases percentages and average crystallite size for $\mathrm{La}_{1-\mathrm{x}} \mathrm{MnO}_{\mathrm{z}}$ composites and $\mathrm{Mn}_{\mathrm{a}} \mathrm{O}_{\mathrm{b}}$ oxides obtained from X-ray diffraction patterns in Fig. 1 .

\begin{tabular}{|c|c|c|c|c|c|c|c|}
\hline \multirow[t]{2}{*}{ Sample } & \multirow[t]{2}{*}{ Unit cell } & \multicolumn{3}{|c|}{ Crystallite phases (\%) } & \multicolumn{3}{|c|}{ Crystallite size $(\mathrm{nm})$} \\
\hline & & $\mathrm{LaMnO}_{3}$ & $\mathrm{Mn}_{3} \mathrm{O}_{4}$ & $\mathrm{Mn}_{2} \mathrm{O}_{3}$ & $\mathrm{LaMnO}_{3}$ & $\mathrm{Mn}_{3} \mathrm{O}_{4}$ & $\mathrm{Mn}_{2} \mathrm{O}_{3}$ \\
\hline $\mathrm{LaMnO}_{\mathrm{z}}$ & Cubic & 100 & 0 & 0 & 16 & 0 & 0 \\
\hline $\mathrm{La}_{0.9} \mathrm{MnO}_{z}$ & Rhombohedral & 97.5 & 2.5 & 0 & 23 & 83 & 0 \\
\hline $\mathrm{La}_{0.7} \mathrm{MnO}_{\mathrm{z}}$ & & 90.2 & 9.8 & 0 & 28 & 41 & 0 \\
\hline $\mathrm{La}_{0.6} \mathrm{MnO}_{\mathrm{z}}$ & Cubic & 79 & 15.5 & 5.5 & 15 & 10 & 59 \\
\hline $\mathrm{La}_{0.5} \mathrm{MnO}_{\mathrm{z}}$ & & 74 & 21.7 & 4.3 & 17 & 29 & 86 \\
\hline $\mathrm{Mn}_{2} \mathrm{O}_{3}$ & Cubic & 0 & 0 & 100 & 0 & 0 & 69 \\
\hline $\mathrm{Mn}_{3} \mathrm{O}_{4}$ & Tetragonal & 0 & 100 & 0 & 0 & 68 & 0 \\
\hline
\end{tabular}

electrocatalytic response of these composites, the Scherrer equation was used to determine the dimensions of crystallite phases. The crystallite size of the cubic perovskite phase (originally around $15-17 \mathrm{~nm}$ ) increases up to $23-28 \mathrm{~nm}$ for the rhombohedral crystal structure, a change that can be easily ascribed to the enlargement of the lattice parameters $[43,46]$. The concentration of $\mathrm{Mn}_{\mathrm{a}} \mathrm{O}_{\mathrm{b}}$ oxides is typically in the range $2.5-21.7 \%$ for $\mathrm{La}_{1-\mathrm{x}} \mathrm{MnO}_{\mathrm{z}}$ samples depending on La:Mn atomic ratio. $\mathrm{Mn}_{3} \mathrm{O}_{4}$ shows different crystallite mean sizes depending on the concentration within the sample. The highest value, $83 \mathrm{~nm}$, is obtained for $\mathrm{La}_{0.9} \mathrm{MnO}_{\mathrm{z}}$, whereas only $10 \mathrm{~nm}$ were measured for $\mathrm{La}_{0.6} \mathrm{MnO}_{z}$. It is worth noting that simple manganese oxides, $\mathrm{Mn}_{3} \mathrm{O}_{4}$ and $\mathrm{Mn}_{2} \mathrm{O}_{3}$, show similar crystallite sizes but $\mathrm{Mn}_{3} \mathrm{O}_{4}$ is constituted by larger particles as observed by SEM, which may affect its electrocatalytic activity towards ORR.

\subsection{Surface chemical composition}

Since surface and bulk compositions of $\mathrm{La}_{1-\mathrm{x}} \mathrm{MnO}_{\mathrm{z}}$ composites and manganese oxides may differ, separate analyses are required.
XPS can be used to characterize the surface of materials and to distinguish Mn oxidation states and different oxygen species, which are relevant for ORR. Fig. 2 shows La 3d, Mn 2p and O 1s corelevel spectra for the different materials. The La 3d region (Fig. 2a) is characterized by two well-separated spin-orbit components at around $834 \mathrm{eV}\left(\mathrm{La} 3 \mathrm{~d}_{5 / 2}\right)$ and $851 \mathrm{eV}\left(\mathrm{La} 3 \mathrm{~d}_{3 / 2}\right)$ showing multiplet structure. The spin-orbit splitting of La $3 \mathrm{~d}$, which is around $16.8 \mathrm{eV}$ for all $\mathrm{La}_{1-\mathrm{x}} \mathrm{MnO}_{\mathrm{z}}$ samples, suggests the presence of lanthanum in the trivalent state $[47,48]$. Since the value of the multiplet splitting is higher than $4 \mathrm{eV}$ for all composites, the presence of lanthanum oxides is evidenced [47]. It can be also observed that La $3 d_{5 / 2}$ and $\mathrm{La}$ $3 \mathrm{~d}_{3 / 2}$ peaks slightly shift to lower binding energies at increasing $\mathrm{Mn}$ concentration. This may be related to the increasing electron density around lanthanum, due to backbonding from manganese to oxygen [49]. The Mn 2p spectra (Fig. 2b) displays two asymmetrical spin-orbit signals at about 641.7 and $653.3 \mathrm{eV}$, which can be attributed to $\mathrm{Mn} 2 \mathrm{p}_{3 / 2}$ and $\mathrm{Mn} 2 \mathrm{p}_{1 / 2}$, respectively [47,50]. The asymmetry of these peaks suggests the presence of different oxidation states of $\mathrm{Mn}$ at the surface. The spin-orbit splitting close
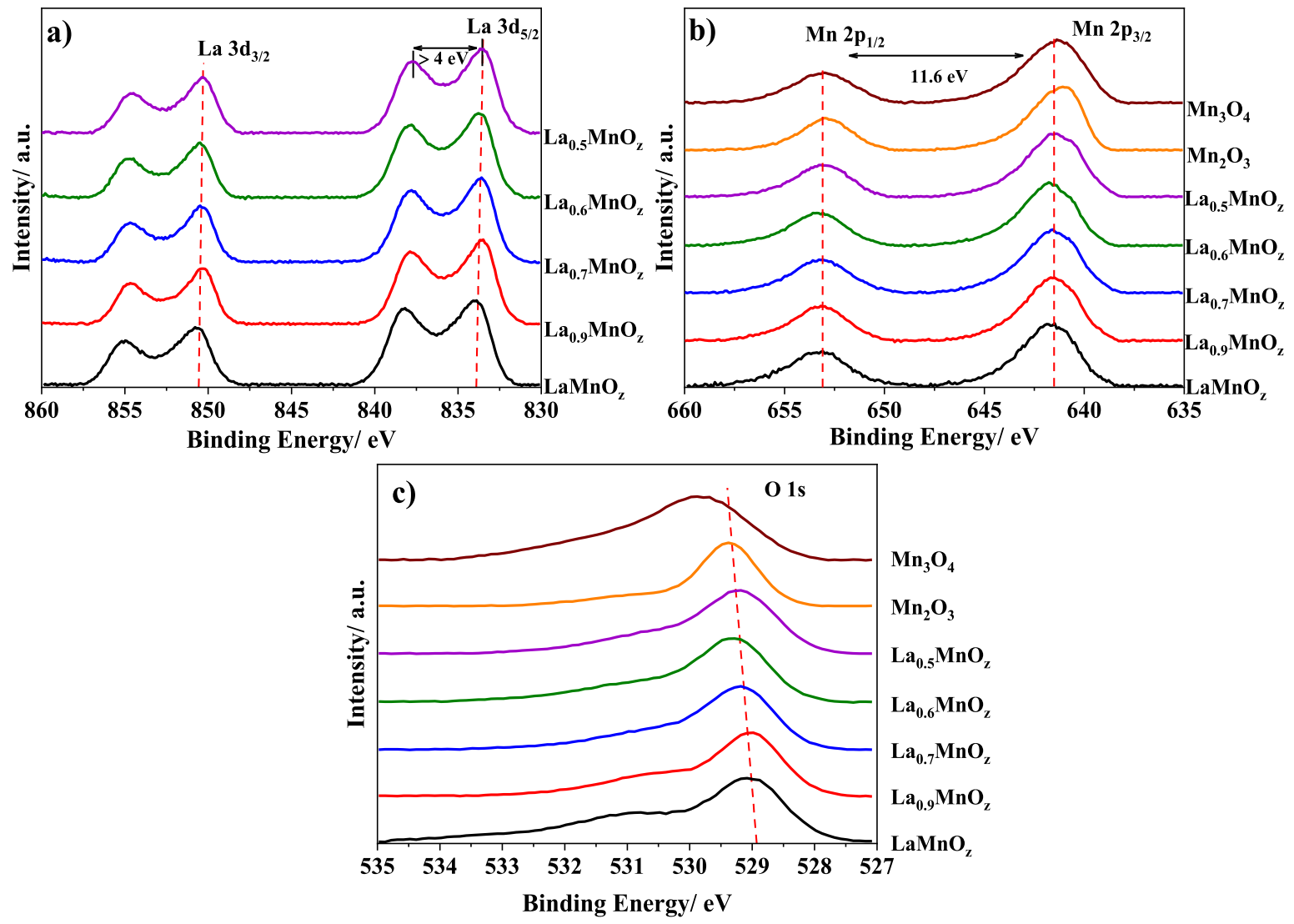

Fig. 2. X-ray photoelectron signals obtained from (a) La 3d; (b) Mn 2p and (c) O 1s spectral regions for $\mathrm{La}_{1-\mathrm{x}} \mathrm{MnO}_{\mathrm{z}} \mathrm{composites} \mathrm{and} \mathrm{Mn}_{\mathrm{a}} \mathrm{O}_{\mathrm{b}}$ oxides. 

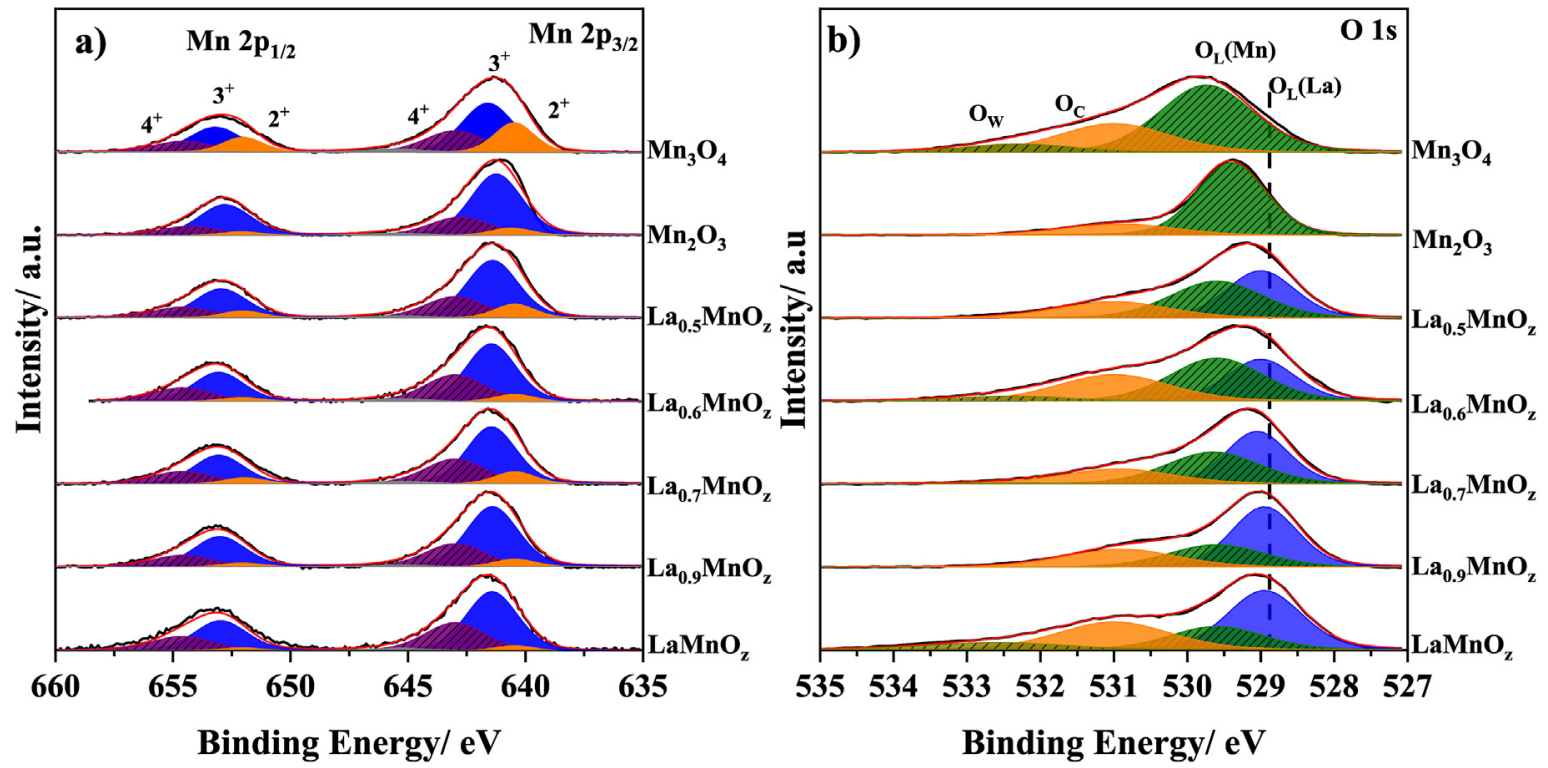

Fig. 3. Deconvolution of X-ray photoelectron spectra signals coming from (a) Mn 2p and (b) 0 1s samples in Fig. 3.

to $11.6 \mathrm{eV}$ points to the presence of surface $\mathrm{Mn}^{3+}$ in $\mathrm{La}_{1-\mathrm{x}} \mathrm{MnO}_{\mathrm{z}}$ composites [51] and this value matches well with that reported for $\mathrm{Mn}_{3} \mathrm{O}_{4}$ [52]. For $\mathrm{Mn}_{2} \mathrm{O}_{3}$, the slightly higher value, close to $11.8 \mathrm{eV}$, agrees with previously reported results [17]. The $O$ 1s spectra (Fig. 2c) of $\mathrm{La}_{1-\mathrm{x}} \mathrm{MnO}_{\mathrm{z}}$ oxides shows a peak at around $529 \mathrm{eV}$, whereas higher binding energies are observed for $\mathrm{Mn}_{2} \mathrm{O}_{3}$ and $\mathrm{Mn}_{3} \mathrm{O}_{4}$ (at around 529.4 and $529.8 \mathrm{eV}$, respectively, which agrees with previous studies [53]). The changes in $O$ 1s spectra at increasing $\mathrm{Mn}$ concentration reveal the progressive formation of manganese oxide phases.

Mn 2p and O 1s spectra of all the samples were deconvoluted in Fig. 3 to quantify the contribution of manganese oxidation states and oxygen species, respectively. The Mn $2 \mathrm{p}_{3 / 2}$ signal (Fig. 3a) was separated into three peaks at around $640.5\left(\mathrm{Mn}^{2+}\right), 641.4\left(\mathrm{Mn}^{3+}\right)$ and $643.0 \mathrm{eV}\left(\mathrm{Mn}^{4+}\right)$. The $\mathrm{Mn} 2 \mathrm{p}_{1 / 2}$ signal resulted in peaks at 652.0 $\left(\mathrm{Mn}^{2+}\right), 653.0\left(\mathrm{Mn}^{3+}\right)$ and $654.6 \mathrm{eV}\left(\mathrm{Mn}^{4+}\right)$ [35,54,55]. Moreover, a satellite can be observed at around $645.4 \mathrm{eV}$, which can be assigned to $\mathrm{Mn}^{2+}$ species [56]. As derived from the relative peak areas, the main oxidation state is $\mathrm{Mn}^{3+}$ (coloured in blue) followed by $\mathrm{Mn}^{4+}$ (purple). $\mathrm{Mn}^{2+}$ oxidation state (orange) is usually present at lower concentration, except for $\mathrm{Mn}_{3} \mathrm{O}_{4}$, whose bulk structure is composed of $\mathrm{Mn}^{2+}$ and $\mathrm{Mn}^{3+}$. Table 2 summarizes the quantification of $\mathrm{Mn}$ main oxidation states obtained by deconvolution. The $\mathrm{O} 1 \mathrm{~s}$ spectra of $\mathrm{La}_{1-\mathrm{x}} \mathrm{MnO}_{\mathrm{z}}$ can be generally deconvoluted into four peaks (Fig. 3b), at around 529, 529.6, 531.0 and $532.6 \mathrm{eV}$. They correspond respectively to lattice oxygen in either lanthanum or manganese oxides $\left(\mathrm{O}_{\mathrm{L}}\right)$, surface adsorbed oxygen species or $\mathrm{OH}^{-}\left(\mathrm{O}_{\mathrm{C}}\right)$, and physisorbed or chemisorbed $\mathrm{H}_{2} \mathrm{O}$ molecules $\left(\mathrm{O}_{\mathrm{W}}\right)$ [35,57]. However, $\mathrm{Mn}_{2} \mathrm{O}_{3}$ exhibits only two contributions at 529.4 and $530.9 \mathrm{eV}$, which are ascribed to $\mathrm{O}_{\mathrm{L}}$ and $\mathrm{O}_{\mathrm{C}}$ [17], whereas $\mathrm{Mn}_{3} \mathrm{O}_{4}$ shows three peaks at 529.7, 531 and $532.3 \mathrm{eV}$ corresponding to $\mathrm{O}_{\mathrm{L}}, \mathrm{O}_{\mathrm{C}}$ and $\mathrm{O}_{\mathrm{W}}$, respectively [52].

EDX technique was used to estimate the bulk composition of $\mathrm{La}_{1-\mathrm{x}} \mathrm{MnO}_{\mathrm{z}}$ composites. Table 2 shows that $\mathrm{Mn} / \mathrm{La}$ atomic ratios, as obtained by EDX, are quite close to nominal values (those derived from the stoichiometry used during synthesis), thus confirming the overall composition of materials. However, XPS values differ significantly, revealing that the surface concentration of lanthanum exceeds nominal values. Similar surface enrichment was reported in some previous studies [47,58]. As expected, the concentration of Mn over the surface increases at decreasing La concentration, which may improve the electrocatalytic performance of these materials towards ORR.

Previous studies reported that the presence of an appropriate amount of $\mathrm{Mn}^{4+}$ species could increase the covalency of the metaloxygen bond and assist the $\mathrm{O}_{2}^{2-} / \mathrm{OH}^{-}$exchange (a significant step of the ORR mechanism) which improves the ORR performance $[33,59]$. Moreover, $\mathrm{Mn}^{4+}$ shows higher oxidation ability than $\mathrm{Mn}^{3+}$, thus accelerating the chemical disproportionation of $\mathrm{HO}_{2}^{-}$and improving the ORR performance [33,60]. A high concentration of $\mathrm{O}_{C}$, which is also associated with oxygen vacancies [23], can enhance the mobility of the oxygen ion [21] and reinforce the covalency of the $\mathrm{B}-\mathrm{O}$ bond, which may facilitate again the $\mathrm{O}_{2}^{2-} / \mathrm{OH}^{-}$ exchange [59].

Table 2

Nominal and experimental atomic ratios for $\mathrm{La}_{1-\mathrm{x}} \mathrm{MnO}_{z}$ composites obtained from EDX and XPS measurements. Deconvolution data obtained from Fig. 3.

\begin{tabular}{|c|c|c|c|c|c|c|}
\hline \multirow[t]{2}{*}{ Sample } & \multirow{2}{*}{$\frac{\text { Nominal }}{\frac{\mathrm{Mn}}{\mathrm{La}}}$} & \multirow{2}{*}{$\frac{\mathrm{EDX}}{\frac{\mathrm{Mn}}{\mathrm{La}}}$} & \multicolumn{4}{|l|}{ XPS } \\
\hline & & & $\frac{\mathrm{Mn}}{\mathrm{La}}$ & $\mathrm{Mn}^{4+} / \mathrm{Mn}^{3+}$ & $\mathrm{O}_{\mathrm{C}} / \mathrm{O}_{\mathrm{L}}$ & Average Mn oxidation state \\
\hline $\mathrm{LaMnO}_{z}$ & 1.00 & 0.99 & 0.58 & 0.55 & 0.47 & 3.29 \\
\hline $\mathrm{La}_{0.9} \mathrm{MnO}_{\mathrm{z}}$ & 1.11 & 1.04 & 0.73 & 0.50 & 0.33 & 3.25 \\
\hline $\mathrm{La}_{0.7} \mathrm{MnO}_{\mathrm{z}}$ & 1.43 & 1.39 & 1.04 & 0.52 & 0.27 & 3.21 \\
\hline $\mathrm{La}_{0.6} \mathrm{MnO}_{\mathrm{z}}$ & 1.67 & 1.67 & 1.20 & 0.55 & 0.43 & 3.27 \\
\hline $\mathrm{La}_{0.5} \mathrm{MnO}_{\mathrm{z}}$ & 2.00 & 2.09 & 1.23 & 0.42 & 0.28 & 3.21 \\
\hline $\mathrm{Mn}_{2} \mathrm{O}_{3}$ & - & - & - & 0.34 & 0.25 & 3.17 \\
\hline $\mathrm{Mn}_{3} \mathrm{O}_{4}$ & - & - & - & 0.51 & 0.51 & 3.02 \\
\hline
\end{tabular}


The $\mathrm{Mn}^{4+} / \mathrm{Mn}^{3+}$ ratio for $\mathrm{La}_{1-\mathrm{x}} \mathrm{MnO}_{\mathrm{z}}$ composites is in the range between 0.42 and $0.55 . \mathrm{La}_{0.5} \mathrm{MnO}_{\mathrm{z}}$ shows the lowest ratio and both $\mathrm{LaMnO}_{\mathrm{z}}$ and $\mathrm{La}_{0.6} \mathrm{MnO}_{\mathrm{z}}$ the highest ones. Since surface $\mathrm{Mn}$ is promoted at increasing $x$ values, it can be assumed that the total concentration of $\mathrm{Mn}^{4+}$ also increases up to its maximum value for $\mathrm{La}_{0.6} \mathrm{MnO}_{z}$ and then drops. It is then expected that $\mathrm{La}_{0.6} \mathrm{MnO}_{\mathrm{z}}$ sample shows the best electrocatalytic behaviour due to the larger concentration of $\mathrm{Mn}^{4+}$ and oxygen vacancies. Among manganese oxides, $\mathrm{Mn}_{3} \mathrm{O}_{4}$ sample shows the highest $\mathrm{Mn}^{4+}$ and oxygen vacancies concentration, but the electrocatalytic performance could be limited by its larger particle size compared to $\mathrm{Mn}_{2} \mathrm{O}_{3}$, as revealed by SEM and XRD. The average oxidation states of $\mathrm{Mn}$, which were calculated after XPS spectral deconvolution, show little differences for $\mathrm{La}_{1-\mathrm{x}} \mathrm{MnO}_{\mathrm{z}}$ composites and, accordingly, the ORR performance is expected to be more determined by the Mn surface concentration. Manganese oxide materials, on the contrary, show significant differences: 3.17 and 3.02 for $\mathrm{Mn}_{2} \mathrm{O}_{3}$ and $\mathrm{Mn}_{3} \mathrm{O}_{4}$, respectively. As the optimum value for proper Mn-oxygen interaction is 3.4, $\mathrm{Mn}_{3} \mathrm{O}_{4}$ is expected to show a lower catalytic performance [61,62].

\subsection{Electrochemical characterization}

The relative concentration of crystal phases and the surface chemistry of $\mathrm{La}_{1-\mathrm{x}} \mathrm{MnO}_{\mathrm{z}}$ composites are both governed by La:Mn atomic ratio. Accordingly, it is expected that the electrochemical properties of the composite materials could be tuned by changing that parameter during the synthesis. The electrochemical characterization of the as-synthesized materials, including the pure manganese oxides mixed with carbon black, was performed by cyclic voltammetry in a $\mathrm{N}_{2}$-saturated atmosphere and the results are depicted in Fig. 3S. These materials exhibit two different voltammetric peaks associated with Mn redox processes [18,28,30]. $\mathrm{Mn}^{2+} / \mathrm{Mn}^{3+}$ oxidation occurs during the forward scan producing peaks at around $0.7 \mathrm{~V}$. Moreover, the presence of a small anodic peak at $0.9 \mathrm{~V}$ in some samples is associated with the formation of $\mathrm{MnOOH}$ species. During the reverse scan, the counter process peaks at around $0.5 \mathrm{~V}$. Moreover, it can be clearly observed that rhombohedral $\mathrm{La}_{1-\mathrm{x}} \mathrm{MnO}_{z}$ composites show a lower double-layer charging current, which can be attributed to their larger crystallites.

Among manganese oxide-based materials, $\mathrm{Mn}_{3} \mathrm{O}_{4} /$ Vulcan shows the lowest double-layer charging current due to the larger particle size of this material. Small voltammetric peaks related to $\mathrm{Mn}$ redox processes can be also distinguished. On the other hand, $\mathrm{Mn}_{2} \mathrm{O}_{3} /$ Vulcan undergoes an oxidation process, which starts at around $0.8 \mathrm{~V}$. This process may be associated with a high concentration of $\mathrm{Mn}^{3+}$ yielding $\mathrm{MnOOH}$ which can be subsequently oxidized to $\mathrm{Mn}^{4+}$ at a higher potential (at around $1.1 \mathrm{~V}$ vs RHE, which was not reached in these CV experiments). In the reverse sweep, the small peak at around $0.75 \mathrm{~V}$ can be related to the reduction related process. Celorrio et al. [28] suggested that the unique activity of $\mathrm{LaMnO}_{3}$ towards ORR is linked to changes in the oxidation state of manganese at potentials close to the formal oxygen redox potential.

\subsection{Electrochemical activity towards ORR}

The electrochemical activity of catalysts was evaluated by means of an RRDE in $0.1 \mathrm{M} \mathrm{KOH}$ and the results are shown in Fig. 4. All $\mathrm{La}_{1-\mathrm{x}} \mathrm{MnO}_{z} /$ Vulcan materials display quite similar behaviour (Fig. 4a), although some differences in the onset potential and limiting current density can be discerned. Generally, samples containing the rhombohedral perovskite phase show less positive onset potential, which suggests that larger crystallite size represents fewer active sites available for the electrochemical reaction. Meanwhile, $\mathrm{La}_{0.6} \mathrm{MnO}_{z}$ oxide shows the highest current density. On
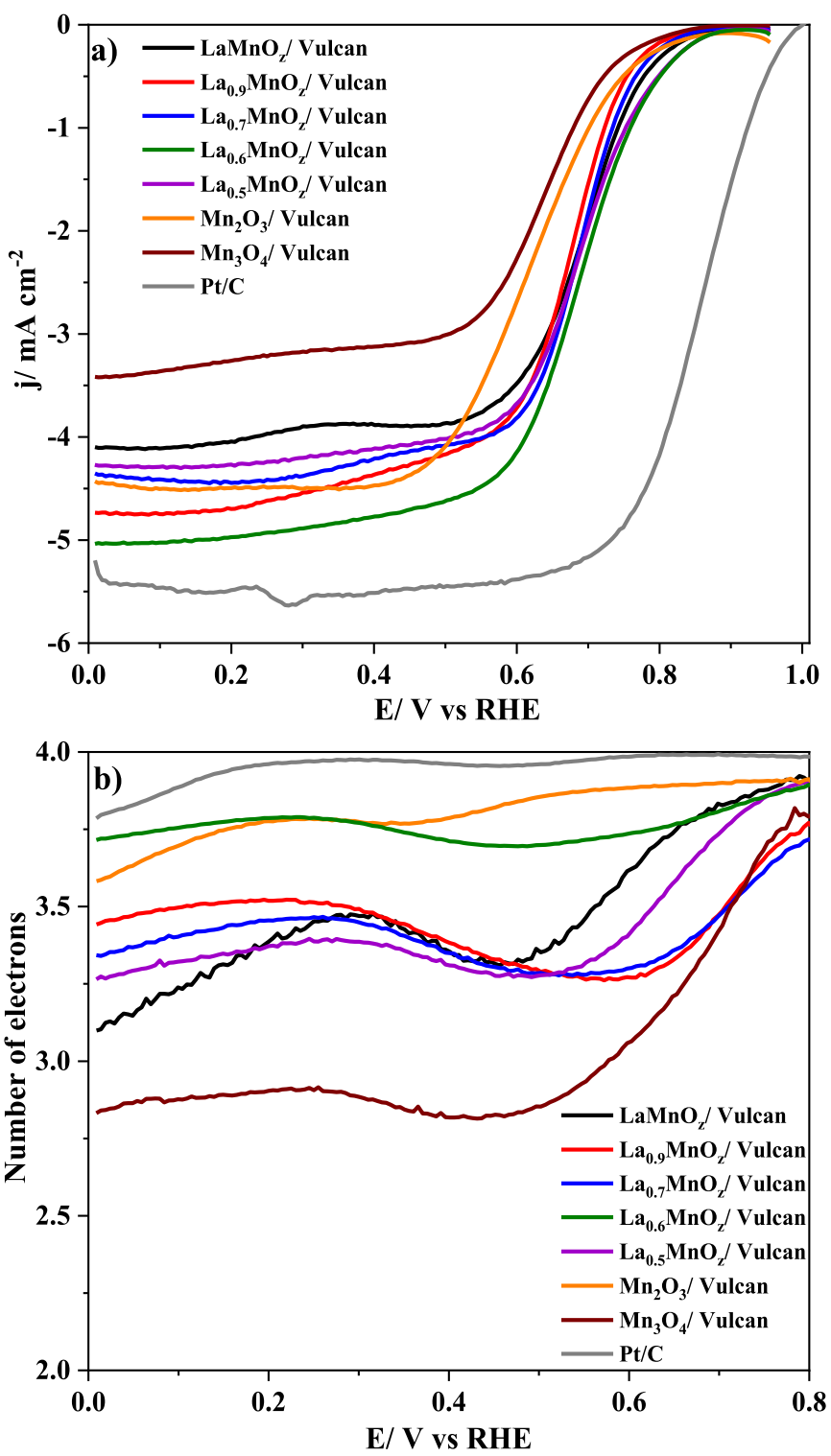

Fig. 4. a) RDE linear sweep voltammograms for $\mathrm{La}_{1-\mathrm{x}} \mathrm{MnO}_{z} /$ Vulcan composites and $\mathrm{Mn}_{\mathrm{a}} \mathrm{O}_{\mathrm{b}} /$ Vulcan in $0.1 \mathrm{M} \mathrm{KOH}$ saturated with $\mathrm{O}_{2}$ at $1600 \mathrm{rpm}$; b) Number of transferred electrons involved in ORR at increasing potential as obtained from Eq. (4) by using the current measured at the ring.

the other hand, a clear difference in the ORR performance exists between manganese oxide-based materials. The $\mathrm{Mn}_{2} \mathrm{O}_{3} /$ Vulcan sample exhibits better electroactivity compared to $\mathrm{Mn}_{3} \mathrm{O}_{4} /$ Vulcan, which may be ascribed to the lower particle size (and larger surface area). The higher average oxidation state of manganese in $\mathrm{Mn}_{2} \mathrm{O}_{3}$ probably improves its electroactivity for ORR.

The number of electrons transferred in ORR is depicted in Fig. $4 \mathrm{~b}$. The reaction proceeds in the range of around 3.3-3.7 for $\mathrm{La}_{1-\mathrm{x}} \mathrm{MnO}_{z} /$ Vulcan materials, being $\mathrm{La}_{0.6} \mathrm{MnO}_{\mathrm{z}} /$ Vulcan the most selective sample for a 4-electron reaction pathway. This result can be explained in terms of the higher concentrations of $\mathrm{Mn}^{4+}$ and oxygen vacancies $\left(\mathrm{O}_{\mathrm{C}}\right)$. Previous studies revealed the importance of these two parameters for a high ORR performance but, in those cases, a partial substitution of B-site cations [23,59] or A-site cations $[32,33]$ was performed to generate $\mathrm{Mn}^{4+}$ and oxygen vacancies. $\mathrm{Mn}_{2} \mathrm{O}_{3}$ materials show the highest selectivity for a 4electron pathway. This finding agrees with a previous study [62] 
reporting that $\mathrm{Mn}_{2} \mathrm{O}_{3}$ could yield less amount of peroxide in this reaction compared to $\mathrm{Mn}_{3} \mathrm{O}_{4}$. ORR can proceed through either a 2electron or a 4-electron pathway in an alkaline medium, being the latter the most desirable because it gives more power and does not produce corrosive peroxide species [63]. On perovskite and spinel materials the mechanism involves 4 electrons and comprises the interaction of a $3 d$ transition metal in an octahedral site with the oxygen-containing species $[31,40,64]$. Two main parameters govern the ORR performance, and both improve after the incorporation of $\mathrm{Mn}^{4+}$ species: on the one hand, the $e_{g}$ orbital of $\mathrm{B}$ site cations filled with one electron promotes $\mathrm{O}_{2}^{2-} / \mathrm{OH}^{-}$displacement. On the other hand, a stronger covalency of the $\mathrm{B}-\mathrm{O}$ bond increases the driving force and, as a result, facilitates the $\mathrm{O}_{2}^{2-} / \mathrm{OH}^{-}$exchange [31].

Previous studies $[40,41]$ reported a synergistic effect between oxides and carbon materials through a strong $\mathrm{C}-\mathrm{O}-\mathrm{Mn}$ interaction that facilitates electron transfer and, consequently, the ORR activity. In addition, the carbon material can act as a co-catalyst by reducing oxygen through a $2+2$ electron pathway. Firstly, $\mathrm{OH}_{2}^{-}$is generated and then, it can be reduced to $\mathrm{OH}^{-}$over the adjacent metal oxide catalytic sites [38,42].

The most significant electrochemical parameters obtained from LSV experiments are shown in Table 3. For the $\mathrm{La}_{1-\mathrm{x}} \mathrm{MnO}_{z} /$ Vulcan set, the onset potential for ORR is higher at $\mathrm{La}_{0.6} \mathrm{MnO}_{z} /$ Vulcan and $\mathrm{La}_{0.5} \mathrm{MnO}_{\mathrm{z}} /$ Vulcan, thus suggesting that catalytic sites are more active in these two samples. The suitable crystallite size of the different phases may explain their better catalytic performance, but the synergy between perovskite and manganese oxides cannot be ruled out, especially for $\mathrm{Mn}_{2} \mathrm{O}_{3}$ oxide. Such an effect was detected in previous studies [62] and used to explain the better ORR performance observed. Although, the total concentration of $\mathrm{Mn}^{4+}$ increases at increasing $x$ values, the selectivity towards the 4-electron pathway at $\mathrm{La}_{0.9} \mathrm{MnO}_{z} /$ Vulcan and $\mathrm{La}_{0.7} \mathrm{MnO}_{\mathrm{z}} /$ Vulcan samples deteriorates, as evidenced by a decrease in the respective number of electrons recorded. This effect is attributed to the presence of $\mathrm{Mn}_{3} \mathrm{O}_{4}$ species. On the contrary, for $\mathrm{La}_{0.6} \mathrm{MnO}_{z} /$ Vulcan and $\mathrm{La}_{0.5} \mathrm{M}-$ $\mathrm{nO}_{z} /$ Vulcan samples the number of electrons increases (3.81 and 3.74 respectively), which can be explained in terms of the higher selectivity of $\mathrm{Mn}_{2} \mathrm{O}_{3}$ to this route. As expected, the increasing amount of surface Mn at higher $x$ values has a positive effect on the limiting current density, mostly because a higher number of the active sites are available for ORR.

According to the Tafel slopes presented in Table 3, the electron transfer kinetics for ORR becomes slightly more favourable at $\mathrm{La}_{1-}$ ${ }_{x} \mathrm{MnO}_{z} /$ Vulcan samples when $\mathrm{x} \geq 0.3$. It can be then derived that a higher surface concentration of $\mathrm{Mn}$ enhances the electrocatalytic performance. Tafel slopes at $\mathrm{La}_{1-\mathrm{x}} \mathrm{MnO}_{\mathrm{z}} /$ Vulcan samples are comprised between 100 and $90 \mathrm{mV} \mathrm{dec}^{-1}$ and, accordingly, the rate-determining step seems to be a combination of the first electron transfer $\left(120 \mathrm{mV} \mathrm{dec}^{-1}\right)$ and the protonation of superoxide to

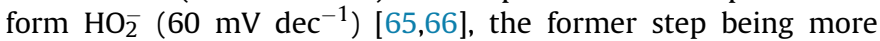
dominant for those composites with $\mathrm{x} \geq 0.3$. On the other hand,

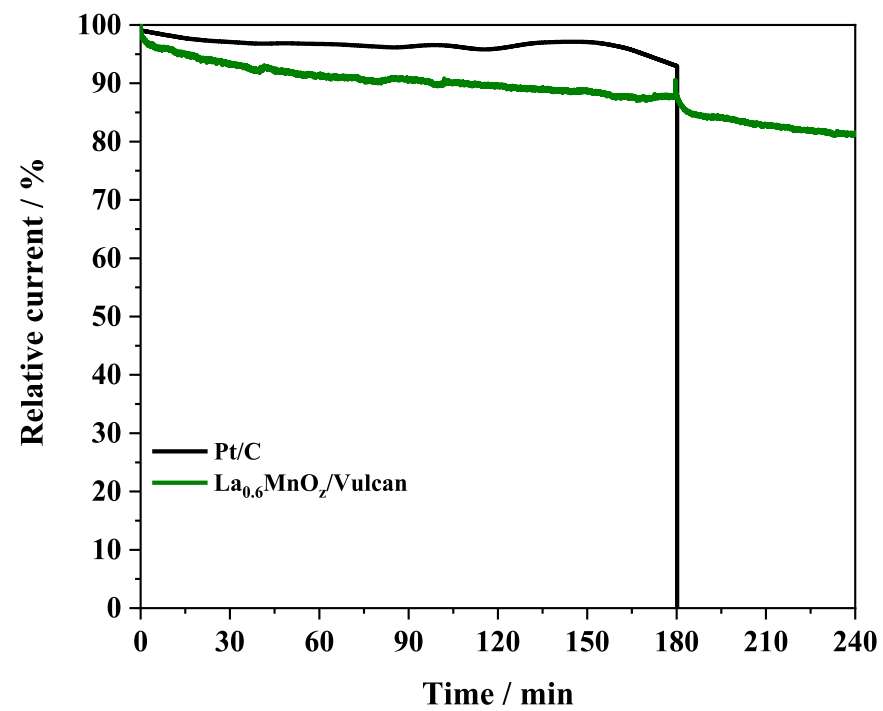

Fig. 5. Comparative stability test for $\mathrm{La}_{0.6} \mathrm{MnO}_{z} / \mathrm{Vulcan}$ composite and $20 \% \mathrm{Pt} / \mathrm{C}$ can accomplished at $0.65 \mathrm{~V}$ and $1600 \mathrm{rpm}$ in $\mathrm{O}_{2}$-saturated $0.1 \mathrm{M} \mathrm{KOH}$ and $25^{\circ} \mathrm{C}$. Methanol was added $180 \mathrm{~min}$ after the beginning of the experiment.

$\mathrm{Mn}_{\mathrm{a}} \mathrm{O}_{\mathrm{b}}$-based materials exhibit high Tafel slopes, thus suggesting that the first electron transfer is the rate-determining step. Although $\mathrm{Mn}_{3} \mathrm{O}_{4} /$ Vulcan shows slightly better kinetics, it provides a lower number of electrocatalytic active sites.

Therefore, if all the electrochemical parameters from LSV curves are considered, the best performance is obtained for $\mathrm{La}_{0.6} \mathrm{MnO}_{\mathrm{z}}$ / Vulcan sample. The stability of this specimen was tested by a chronoamperometric technique and the results are shown in Fig. 5. The experiment was performed on an RRDE at $1600 \mathrm{rpm}$ in $\mathrm{O}_{2}$ saturated $0.1 \mathrm{M} \mathrm{KOH}$ electrolyte and at a constant potential of $0.65 \mathrm{~V}$ [67]. The commercial Pt/C sample was tested under the same experimental conditions to compare the stability of the synthesized material. After $3 \mathrm{~h}$ at $0.65 \mathrm{~V}$, methanol was added to the working electrolyte until 1.0 M concentration was reached. As expected, the Pt-based catalyst retains almost 95\% of the initial current after $3 \mathrm{~h}$. However, after methanol addition, the current drops suddenly to zero because the active metal is poisoned with CO coming from methanol decomposition/oxidation. The activity of $\mathrm{La}_{0.6} \mathrm{MnO}_{z} /$ Vulcan composite shows a slow decay which tends to stabilize at around 150-180 min. After methanol addition, the composite exhibits high tolerance to poisoning, with a minor current drop of around $10 \%$ recorded at the end of the experiment. From the results of this test, it can be concluded that $\mathrm{La}_{0.6} \mathrm{MnO}_{z} /$ Vulcan composite shows a good electrocatalytic performance which makes it a promising alternative to platinum-based electrocatalysts for the ORR in an alkaline medium.

Table 3

Onset potential, number of electrons, limiting current density and Tafel slope obtained for the ORR reaction for the samples mixed with carbon black.

\begin{tabular}{|c|c|c|c|c|}
\hline Sample & $\boldsymbol{E}_{\text {onset }} / \mathrm{V}\left(\right.$ at $\left.-0.10 \mathrm{~mA} \mathrm{~cm}^{-2}\right)$ & $\boldsymbol{n}_{\boldsymbol{e}^{-}}$(at $0.7 \mathrm{~V}$ vs RHE) & $\boldsymbol{j}_{\text {lim }} / \mathrm{mA} \mathrm{cm}^{-2}$ (at $\left.0.4 \mathrm{~V}\right)$ & Tafel slope $/ \mathrm{mV} \mathrm{dec}{ }^{-1}$ \\
\hline $\mathrm{LaMnO}_{\mathrm{z}} /$ Vulcan & 0.84 & 3.83 & -3.87 & 102 \\
\hline $\mathrm{La}_{0.9} \mathrm{MnO}_{\mathrm{z}} /$ Vulcan & 0.83 & 3.47 & -4.37 & 101 \\
\hline $\mathrm{La}_{0.7} \mathrm{MnO}_{\mathrm{z}} /$ Vulcan & 0.84 & 3.47 & -4.21 & 96 \\
\hline $\mathrm{La}_{0.6} \mathrm{MnO}_{\mathrm{z}} /$ Vulcan & 0.87 & 3.81 & -4.78 & 90 \\
\hline $\mathrm{La}_{0.5} \mathrm{MnO}_{\mathrm{z}} /$ Vulcan & 0.87 & 3.74 & -4.11 & 89 \\
\hline $\mathrm{Mn}_{2} \mathrm{O}_{3} /$ Vulcan & 0.86 & 3.90 & -4.47 & 158 \\
\hline $\mathrm{Mn}_{3} \mathrm{O}_{4} /$ Vulcan & 0.81 & 3.42 & -3.12 & 133 \\
\hline $\mathrm{Pt} / \mathrm{C}$ & 0.98 & 3.99 & -5.51 & 60 \\
\hline
\end{tabular}




\section{Conclusions}

$\mathrm{La}_{1-\mathrm{x}} \mathrm{MnO}_{z}$ electrocatalysts were synthesized by means of a solgel method. As expected, different La:Mn ratio during the synthesis generates different crystal phases and modifies the Mn surface concentration. The presence of a cubic perovskite phase leads to a better electrocatalytic performance in ORR because the compounds show smaller size. Among the synthesized samples, $\mathrm{La}_{0.6} \mathrm{MnO}_{\mathrm{z}} /$ Vulcan exhibits the best electrocatalytic response towards ORR. This may be due to its higher $\mathrm{Mn}^{4+} / \mathrm{Mn}^{3+}$ ratio and number of oxygen vacancies, which increase the electrical conductivity and promotes the covalency of the $\mathrm{B}-\mathrm{O}$ bond. Moreover, the high $\mathrm{Mn}^{4+}$ content affects positively the ORR activity because its higher oxidation ability facilitates the chemical disproportionation reaction of $\mathrm{HO}_{2}^{-}$, thus increasing the overall reaction kinetics. The presence of manganese oxides, particularly $\mathrm{Mn}_{2} \mathrm{O}_{3}$, also improves the catalytic performance of $\mathrm{LaMnO}_{3}$ due to a possible synergistic effect between both oxides. It was observed a synergistic effect between metal oxides and carbon material that improves the electron transfer kinetics in ORR. The carbon material also acts as a co-catalyst favouirng the overall reaction. Apart from the suitable electrocatalytic performance in ORR, the $\mathrm{La}_{0.6} \mathrm{MnO}_{z} /$ Vulcan composite shows good tolerance to methanol poisoning, making it a promising alternative to platinum-based materials for alkaline fuel cells.

\section{Credit author statement}

Jhony X. Flores-Lasluisa: Conceptualization, Methodology, Investigation, Writing - original draft. Francisco Huerta: Conceptualization, Methodology, Supervision, Investigation, Writing review \& editing. Diego Cazorla-Amorós: Conceptualization, Methodology, Supervision, Writing - review \& editing. Emilia Morallón: Conceptualization, Methodology, Project administration, Supervision, Writing - review \& editing, Funding acquisition.

\section{Declaration of competing interest}

The authors declare that they have no known competing financial interests or personal relationships that could have appeared to influence the work reported in this paper.

\section{Acknowledgements}

The authors thank to the Ministerio de Ciencia e Innovación (PID2019-105923RB-I00) for financial support. J.X.F.-L. gratefully acknowledges MINECO for financial support through an FPI contract (BES-2017-081598).

\section{Appendix A. Supplementary data}

Supplementary data to this article can be found online at https://doi.org/10.1016/j.energy.2022.123456.

\section{References}

[1] Li M, Bi X, Wang R, Li Y, Jiang G, Li L, Zhong C, Chen Z, Lu J. Matter 2020;2: 32-49.

[2] Banham D, Ye S. ACS Energy Lett 2017;2:629-38.

[3] Kong J, Cheng W. Cuihua Xuebao/Chinese. J Catal 2017;38:951-69.

[4] Hong WT, Risch M, Stoerzinger KA, Grimaud A, Suntivich J, Shao-Horn Y. Energy Environ Sci 2015;8:1404-27.

[5] Xu GR, Hui JJ, Huang T, Chen Y, Lee JM. J Power Sources 2015;285:393-9.

[6] Chaisubanan N, Maniwan W, Hunsom M. Energy 2017;127:454-61.

[7] Beltrán-Gastélum M, Salazar-Gastélum MI, Félix-Navarro RM, Pérez-Sicairos S, Reynoso-Soto EA, Lin SW, Flores-Hernández JR, Romero-Castañón T, AlbarránSánchez IL, Paraguay-Delgado F. Energy 2016;109:446-55.
[8] Osgood H, Devaguptapu SV, Xu H, Cho J, Wu G. Nano Today 2016;11:601-25. [9] Goswami C, Hazarika KK, Bharali P. Mater Sci Energy Technol 2018;1:117-28.

[10] Tan P, Chen B, Xu H, Cai W, He W, Ni M. Energy 2019;166:1241-8.

[11] Yang J, Wang J, Ma S, Ke B, Yu L, Zeng W, Li Y, Wang J. Phys E Low Dimension Syst Nanostruct 2019;109:191-7.

[12] Zhang Z, Zhou D, Liao J, Bao X, Luo S. J Alloys Compd 2019;786:134-8.

[13] Ensafi AA, Heydari-Soureshjani E, Afiyuni SS, Rezaei B. Int J Hydrogen Energy 2019;44:16497-506.

[14] Dessie Y, Tadesse S, Eswaramoorthy R, Abebe B. J Sci Adv Mater Dev 2019;4: 353-69.

[15] Gao S, Geng K. Nano Energy 2014;6:44-50.

[16] Najam T, Cai X, Aslam MK, Tufail MK, Shah SSA. Int J Hydrogen Energy 2020;45:12903-10.

[17] Hazarika KK, Goswami C, Saikia H, Borah BJ, Bharali P. Mol Catal 2018;451: 153-60.

[18] Abrego-Martínez JC, Wang Y, Moreno-Zuria A, Wei Q, Cuevas-Muñiz FM, Arriaga LG, Sun S, Mohamedi M. Electrochim Acta 2019;297:230-9.

[19] Lee E, Jang JH, Kwon YU. J Power Sources 2015;273:735-41.

[20] Li C, Han X, Cheng F, Hu Y, Chen C, Chen J. Nat Commun 2015;6:1-8.

[21] Lee DU, Park MG, Park HW, Seo MH, Ismayilov V, Ahmed R, Chen Z. Electrochem Commun 2015;60:38-41.

[22] Liu X, Gong H, Wang T, Guo H, Song L, Xia W, Gao B, Jiang Z, Feng L, He J. Chem - An Asian J 2018;13:528-35.

[23] Hu J, Wang L, Shi L, Huang H. Electrochim Acta 2015;161:115-23.

[24] Celorrio V, Calvillo L, Granozzi G, Russell AE, Fermin DJ. Top Catal 2018;61: 154-61.

[25] Kozuka H, Ohbayashi K, Koumoto K. Sci Technol Adv Mater 2015;16:26001.

[26] Hyodo T, Hayashi M, Miura N, Yamazoe N. J Electrochem Soc 1996;143: L266-7.

[27] Yadav K, Singh MP, Razavi FS, Varma GD. Mater Sci Eng B Solid State Mater Adv Technol 2012;177:1219-25.

[28] Celorrio V, Dann E, Calvillo L, Morgan DJ, Hall SR, Fermin DJ. Chemelectrochem 2016;3:283-91.

[29] Ashok A, Kumar A, Bhosale RR, Almomani F, Malik SS, Suslov S, Tarlochan F. J Electroanal Chem 2018;809:22-30.

[30] Kéranguéven G, Royer S, Savinova E. Electrochem Commun 2015;50:28-31.

[31] Suntivich J, Gasteiger HA, Yabuuchi N, Nakanishi H, Goodenough JB, ShaoHorn Y. Nat Chem 2011;3:546-50.

[32] Miao H, Wang Z, Wang Q, Sun S, Xue Y, Wang F, Zhao J, Liu Z, Yuan J. Energy 2018; $154: 561-70$.

[33] Zhao Y, Hang Y, Zhang Y, Wang Z, Yao Y, He X, Zhang C, Zhang D. Electrochim Acta 2017;232:296-302.

[34] Xu K, Lin X, Wang X, Li L, Zhu Z, Tian Y. Appl Surf Sci 2018;459:782-7.

[35] Elsiddig ZA, Xu H, Wang D, Zhang W, Guo X, Zhang Y, Sun Z, Chen J. Electrochim Acta 2017;253:422-9.

[36] Park HW, Lee DU, Park MG, Ahmed R, Seo MH, Nazar LF, Chen Z. ChemSusChem 2015;8:1058-65.

[37] Kostuch A, Gryboś J, Indyka P, Osmieri L, Specchia S, Sojka Z, Kruczała K. Catal Sci Technol 2018;8:642-55.

[38] Ryabova AS, Bonnefont A, Simonov PA, Dintzer T, Ulhaq-Bouillet C, Bogdanova YG, Tsirlina GA, Savinova ER. Electrochim Acta 2017:246:643-53.

[39] Liu J, Jin X, Song W, Wang F, Wang N, Song Y. Chin J Catal 2014;35:1173-88.

[40] Li T, Liu J, Jin X, Wang F, Song Y. Electrochim Acta 2016;198:115-26.

[41] Flores-Lasluisa JX, Huerta F, Cazorla-Amorós D, Morallon E. Nanomaterials 2020;10:2394.

[42] Poux T, Napolskiy FS, Dintzer T, Kéranguéven G, Istomin SY, Tsirlina GA, Antipov EV, Savinova ER. Catal Today 2012;189:83-92.

[43] Flores-Lasluisa JX, Huerta F, Cazorla-Amorós D, Morallón E. J Colloid Interface Sci 2019;556:658-66.

[44] Waseda Y, Matsubara E, Shinoda K. X-ray diffraction crystallography. Berlin, Heidelberg: Springer Berlin Heidelberg; 2011.

[45] Chen YF, Lee CY, Yeng MY, Chiu HT. J Cryst Growth 2003;247:363-70.

[46] Salman A ul R, Hyrve SM, Regli SK, Zubair M, Enger BC, Lødeng R, Waller D, Rønning M. Catalysts 2019;9:429.

[47] Zhang C, Wang C, Zhan W, Guo Y, Guo Y, Lu G, Baylet A, Giroir-Fendler A. Appl Catal B Environ 2013;129:509-16.

[48] O'Connell M, Norman A, Hüttermann C, Morris M. Catal Today 1999;47: $123-32$.

[49] Zhao X, Yang Q, Cui J. J Rare Earths 2008;26:511-4.

[50] Sinquin G, Hindermann JP, Petit C, Kiennemann A. Catal Today 1999;54: 107-18.

[51] Mondal P, Bhattacharya D, Maity A, Chakrabarti O, Maidul Islam AKM, Mukherjee M. J Appl Phys 2011;109.

[52] Liu J, Jiang L, Zhang T, Jin J, Yuan L, Sun G. Electrochim Acta 2016;205:38-44.

[53] http://Srdata.Nist.Gov/Xps/; 2017.

[54] Xue Y, Miao H, Sun S, Wang Q, Li S, Liu Z. J Power Sources 2017;342:192-201.

[55] Liu M, Wang Y, Cheng Z, Zhang M, Hu M, Li J. Appl Surf Sci 2014;313:360-7.

[56] Oku M, Hirokawa K, Ikeda S. J Electron Spectrosc Relat Phenom 1975;7: $465-73$

[57] Miao H, Wu X, Chen B, Wang Q, Wang F, Wang J, Zhang C, Zhang H, Yuan J, Zhang Q. Electrochim Acta 2020;333:135566.

[58] Kéranguéven G, Ulhaq-Bouillet C, Papaefthimiou V, Royer S, Savinova E. Electrochim Acta 2017;245:156-64.

[59] Lv Y, Li Z, Yu Y, Yin J, Song K, Yang B, Yuan L, Hu X. J Alloys Compd 2019;801: 19-26. 
[60] Zhao Y, Liu T, Shi Q, Yang Q, Li C, Zhang D, Zhang C. Green Energy Environ 2018:3:78-85

[61] Wei C, Feng Z, Scherer GG, Barber J, Shao-Horn Y, Xu ZJ. Adv Mater 2017;29: $1-8$.

[62] Stoerzinger KA, Risch M, Han B, Shao-Horn Y. ACS Catal 2015;5:6021-31.

[63] Zhang T, Anderson AB. Electrochim Acta 2007;53:982-9.
[64] Wang Y, Cheng H. J Phys Chem C 2013;117:2106-12.

[65] Shinagawa T, Garcia-Esparza AT, Takanabe K. Sci Rep 2015;5:1-21.

[66] Alexander CT, Abakumov AM, Forslund RP, Johnston KP, Stevenson KJ. ACS Appl Energy Mater 2018;1:1549-58.

[67] Liu K, Li J, Wang Q, Wang X, Qian D, Jiang J, Li J, Chen Z. J Alloys Compd 2017;725:260-9. 